\title{
Freud, Frankenstein and our fear of robots: projection in our cultural perception of technology
}

\author{
Michael Szollosy ${ }^{1}$
}

Received: 16 April 2014/ Accepted: 1 February 2016/Published online: 26 February 2016

(c) The Author(s) 2016. This article is published with open access at Springerlink.com

\begin{abstract}
This paper examines why robots are so often presented as monstrous in the popular media (e.g. film, newspapers), regardless of the intended applications of the robots themselves. The figure of the robot monster is examined in its historical and cultural specificity-that is, as a direct descendent of monsters that we have grown accustomed to since the nineteenth century: Frankenstein, Mr. Hyde, vampires, zombies, etc. Using the psychoanalytic notion of projection, these monsters are understood as representing human anxieties regarding the dehumanising tendencies of science and reason, and regarding a perceived transformation in human nature over the last two hundred years. In analysing these anxieties, we can therefore gain insight into the fears-genuine or naïve-that the public harbours towards new advancements in technology; these insights can then inform those working with and designing living machines as to how their inventions might be received.
\end{abstract}

Keywords Robots · Freud - Anxiety - Terminator . Asimov · Čapek

\section{Introduction}

Why are we afraid of robots? We are not, of course, only afraid of robots, and there is a growing body of evidence to demonstrate that our attitudes to robots are becoming more positive, or that we are at least more ambivalent in our perceptions. But the robots that continue to dominate the

Michael Szollosy

M.Szollosy@sheffield.ac.uk

1 Department of Psychology, University of Sheffield, Sheffield S10 2TP, UK popular imagination-in newspaper headlines, film, television and video games-demonstrate a complex array of anxieties that we harbour towards the very idea of robots, cyborgs, AI and imagined future technologies more generally. ${ }^{1}$

To understand why we are afraid of robots, it is necessary to remind ourselves of what sort of robots it seems that people actually fear. The public are, most likely, unlikely to be afraid of the robots in university labs, the real robots that exist right now, or the sort of robots or AI with which we are already engaging every day. People are much more worried about the Terminators, those near-human cyborgs such as those we've seen in Blade Runner, the less-thanhuman slaves that rise in I, Robot, or the Borg of Star Trek. People fear the sort of robots that tabloid newspaper editors tell us are going to be walking the streets tomorrow, the ones that inspire headlines such as 'Rise of the Terminatorstyle robots that can decide when and who to kill, warns expert $^{2}$ or 'Rise of the Cybermen: The Terminator-style bionic ear that could give people "superman" hearing, ${ }^{3}$ or 'Man given "terminator-like" prosthetic limb" ${ }^{4}$ or 'Robot

\footnotetext{
${ }^{1}$ Here, I use the term 'robot' broadly, to refer to a range of new technologies, and imagined technologies, which also includes what might properly be called cyborgs, or artificial intelligence, or teleoperative machines, etc. Since the popular imagination does not seem to discriminate, and instead regards all of these technologies as a sort of nebulous, ill-defined 'other', it is not important to do so here. It is better, in fact, to look at these fears more generally, in order to fully understand the nature and source of the beliefs.

${ }^{2}$ http://www.dailymail.co.uk/sciencetech/article-1204072/WarningRise-Terminator-style-robots-decide-kill.html\#ixzz2lwfSD2zc.

${ }^{3}$ http://www.dailymail.co.uk/sciencetech/article-2318279/Scientistscreate-breakthrough-bionic-ear-using-cybernetics-Terminator-stylemachines-next.html\#ixzz2lwfklGjm.

${ }^{4}$ http://www.telegraph.co.uk/news/science/science-video/9656189/ Man-given-terminator-like-prosthetic-limb.html.
} 
vacuum cleaner "attacks" South Korean housewife's hair'. 5

These images and imaginings provide us with a wealth of evidence, not as to what robots are really like, or might really be like one day, but as to what people genuinely fear. Like all of the monsters human cultures have created over the millennia, from AI to zombies, from Medusa to Cybermen, the monsters we imagine are not real, but offer tremendous insights into the very real anxieties and fears of human beings in a particular cultural context.

There are a myriad of possible answers as to why we are afraid of robots, most of which have at least some validity in specific contexts. The answers that we tend to favour will depend on our theoretical predispositions, of course, and our own disciplinary interests. Coming from background that looks at the products of our culture (literature, film, etc.) from a psychoanalytic, post-Freudian perspective, I would suggest that our fear of robots, cyborgs, AI, etc., could represent

a fear of death, or annihilation

a fear of individual disintegration and being subsumed within a collective identity

a fear of the 'dead mother' (Green 1993), the unresponsive, empty container that is incapable of responding to us in a meaningful, emotional way $^{6}$ the (predictable) Oedipal fear of the father (the law, social reality, or the return of our own violent impulses) or, more importantly, the fear of the castrating son, the progeny that returns to destroy us.

Each of these explanations can be applied to the popular conceptions of the robot as a mindless, ruthless, incessant, destructive automaton. However, in this paper I would like to focus on something rather different: an understanding of destructive, persecuting robots as projections of our own (unconscious) human selves. This explanation is not exclusive, and embraces many of these other ideas, while simultaneously grasping why these monsters are so profoundly frightening to twentieth- and twenty-first-century audiences.

That the Terminator, the Borg, Cybermen and their descendants-with their slow, sometimes awkward but irrepressible movement, and their obsessive, single purpose-resemble both Frankenstein's monster and zombies is also a clue to their origins, and the anxieties that they arouse in the public imagination. For when we consider robot monsters, we need to regard them within the context of an entire history of monsters that have been imagined

\footnotetext{
5 http://www.telegraph.co.uk/news/worldnews/asia/southkorea/113 99713/Robot-vacuum-cleaner-attacks-South-Korea-housewifes-hair. html.

${ }^{6}$ This is the theme I have explored elsewhere, for example, in 'Why are We Afraid of Robots?: The Role of Projection in the Popular Conception of Robots'.
}

over the centuries-ghosts haunting ancient castles, vampires, werewolves, Frankenstein, Mr. Hyde, atomic dinosaurs, aliens and zombies are all the direct ancestors of The Terminator, HAL 9000, the andys in Do Androids Dream of Electric Sheep? and all the other bad robots we've been subjected to over the last eighty or so years, since Rossum's Universal Robots and Rotwang's Maria. Our robotic monsters are part of a very specific cultural, social and historical context, and by examining this context we can gain a much better understanding of what it we are really afraid of. More pragmatically, for those that would design real robots, such an analysis might provide invaluable insights into how to address public concerns and how to build robots that are more readily accepted by an often sceptical public.

\section{Frankenstein, the modern Prometheus}

Frankenstein and his monster emerge, if not at the very beginning, at a specific point very early in our modern (mis)understanding of robots. The influential science-fiction writer Isaac Asimov had an idea of the 'Frankenstein Complex' (Asimov 1947), which, for Asimov, is a compelling account for our fear of technology. Frankensteinand here we refer to the scientist, not the monster-is a culturally specific Faust, the mad scholar who seeks dangerous knowledge and who desires to supersede God (cf. Gill Karamjit 2013; Schuler 2013). Frankenstein, like Faust, is a victim of hubris and demonstrates that human endeavour, science and technology, whatever their noble intentions, inevitably create a monster that will gain autonomy and return to haunt us.

We see this fundamental archetype ${ }^{7}$ time and again in our fantasies of monstrous robots. In Blade Runner, for example, Scott's (1982) cinematic adaptation of Dick's (1968) novella, Do Android's Dream of Electric Sheep?, the andy Rory Batty tracks down Dr. Tyrell, his creator, and demands 'I want more life, Father!'. Similarly, when Harrison Ford's Rick Deckard is trying to make Rachel Rosen believe that she is an android, he reminds her of a memory from her childhood, thinking that this intimate knowledge proves his case beyond doubt: One summer in Rachael's youth, there was a spider outside her window, orange body, green legs. Rachael watches this spider weave a web all summer, then one day there appears a big egg in the web. The egg hatches, and a hundred baby spiders come out, and they eat their mother.

One can easily regard these to be classical Freudian fantasies of being superseded (devoured) by ones

\footnotetext{
7 In using this word I wish in no way to endorse Carl Jung's use of the term/concept or ideas.
} 
progeny; Freud himself might have pointed to the Greek myths of Cronos and Uranus, or Zeus and Cronus-divine versions of the familiar Oedipus-Laius story to which Freud so often turned, in which the son rises to vanquish the father, and so proving that we sow the seeds of our own destruction. And there is certainly some validity in such a reading; however, this is not the only lesson that can be garnered from the Frankenstein mythology.

From Frankenstein, too, we see the old story of forbidden knowledge and its consequences, and the role of hubris, that over-reaching pride and arrogance that leads to the downfall of Greek protagonists. For us today, these aspects of the story seem less vital than they were to the ancient Greeks, with their stories of Prometheus and Oedipus revealing something intrinsic to their conception of human nature. These facets of the story, however, have nevertheless served to remind audiences over the last two hundred years that we create the monsters that destroy us, or are at least complicit in the creation. But while this, too, is a useful starting place, the re-imaginings of the Frankenstein myth in robotic monsters are not merely suggesting that it is the hubris, or forbidden knowledge, or the Evil Scientist that we must fear, but something more nuanced and slightly more complex, which becomes apparent if we look in more detail the historical context of Frankenstein.

For the Romantics, Frankenstein is not a monster but a 'modern Prometheus', as Mary Shelley's book (1818) is subtitled. Frankenstein is a hero because he represents the best qualities of the individual, or the ideal of the Artist, as it was newly conceived in the Romantic imagination. (This is something that we in the twenty-first century have inherited, with slight modifications). This individual, a version of the Übermensch, is ambitious, ungoverned by any authority; he boldly and nobly drags the human race forward, in spite of the pitchfork-wielding mobs that would see humanity held back. The Romantics regularly made heroes of such figures, as we can see in Goethe's reworkings of the stories of Faust and Prometheus, Byron's ode to Prometheus, and Percy Shelley's play Prometheus Unbound and in the many other works on similar themes that followed soon thereafter.

The Romantics, then, were not afraid of Frankenstein. But we cannot say that they were completely, universally enamoured of this figure, either. Shelley's Gothic novel is perhaps the best example that demonstrates a more ambivalent relationship with this hero. And ambivalence does not mean indifference, as it now so often (incorrectly) used. The Romantics recognised in the Promethean hero both positive and negative aspects of this ideology, and while they might have lionised this figure, they also, at times, saw a darker side to him.
It is in the darker side of this modern Prometheus that we see the Romantics offering some of the same lessons about the over-reaching power of human ambition, about the hubris of invention. But we also see another theme in Romantic and Gothic literature (which of course was not accidentally contemporary with Romanticism): the idea not only that we create the monsters that destroy us, but that we ourselves are becoming those monsters. The monsters in the early Gothic tales portray the ghosts of ancient aristocrats living in the dilapidated castles outside the reaches of modern urban reason. ${ }^{8}$ With Romanticism, however, and nineteenth-century Gothic tales, we see a new kind of monster: monsters that live among us in our cities of reason (Dracula), that we are building from our scientific invention (Frankenstein), or that lie hidden in our unconscious, animalistic selves (Mr. Hyde).

And it is in this context that we need to understand our present-day robot monsters, as part of this two-hundredyear tradition (for we are still in many ways living in the post-Romantic period). When we see Frankenstein in the context of robots, we realise that it is not just technology that we fear, or that technology will gain autonomy and move beyond our control. Rather, looking at Frankenstein, we learn that what we fear is the very quality of ourselves that enables us to create the monster; partly, this is ambition, hubris, etc., but also, and more specifically in this cultural context, we are becoming the robots that we so fear. We fear becoming an empty, mechanical shell of cold, unfeeling rationalism. We are afraid of losing, or that we have already lost, the very qualities that we deem to define us as human.

What we fear in the robot is not just that they are soulless and mechanical, but that we ourselves have become soulless and mechanical, as we are increasingly governed, like Frankenstein, by rationalism and scientific method. We fear the consequences of the 'art' that creates the monster - that our devotion to science and industry, reason and rationality is rendering us less human. The robotic monsters that we see on our screens and in the pages of our novels and newspapers are in fact projections: our fears about ourselves and our world put out there, seen as something other rather than ourselves.

\section{Projections}

Projection is an idea with its roots in Freudian psychoanalysis, but has been considerably enriched by Freud's disciples and contemporary psychoanalytic clinical and cultural theory. The concept of projection tries to describe object relations, that is, the way that people relate to

${ }^{8}$ See, for example, The Castle of Otranto, The Monk. 
things-usually other people, but also other material and non-material objects in their world. Ideas of projection, and the related notion of projective identification, are used in cultural studies to provide compelling explanations for phenomenon as diverse as Nazism and teenage crushes, racism and sports spectatorship.

With projection, it is believed that in psychological fantasy we split off parts of ourselves-feelings, thoughts, or fantasies-and 'project' them into something else-a person, an object, or even a symbol or an idea-which can then be regarded as a sort of container for these projections (cf. Klein 1946; Bion 1962; Anzieu 1984). Sometimes, good parts of the self are projected into containers, for safe keeping; for example, one may project a good part of the self into a container so that it can identify with that part in another. This idea of projective identification can be seen in cultural phenomena such as nationalism, wherein individual people project their own positive qualities (say, resilience) into a symbol, or an idea, or a leader, and that shared association provides collective cohesion, a group identity (cf. Young 1994). Projective identification also provides the basis for understanding empathy, which can be increasingly seen to be a key characteristic in the very way we define and distinguish ourselves as human-see, for example, Do Androids Dream of Electric Sheep?, Blade Runner, The Terminator. ${ }^{9}$

On the other hand, sometimes negative parts of the self are projected into a container (and in practice it is usually a combination of good and bad parts that are projected). Bad parts of the self-violent fantasies, hatred, anxieties, for example - can be projected away from the self, in an act of disavowal. In keeping such bad elements at bay, the self can be thought of as pure and all good. When such projections find a home in another, that container is then imagined the source of that badness, as the hatred and violence are disowned by the self; the container then becomes a persecuting figure as the hatred and violence that is projected out returns in the form of the other.

Though Freud introduced the notion of projection, psychoanalytic thinking since has elevated this idea to greater, or even of the utmost, importance. Projections and projective identifications are, for many, at the very centre of human communications and human experience. But most importantly for our purposes here, projections can be

\footnotetext{
${ }^{9}$ We sometimes project positive qualities into robots, which can be a source of optimism for technology, or, more radically, utopian fantasies about the possibilities offered by robots and AI, but this is something for another study. However, if we were to look at how positive projection (which isn't necessarily a good thing) works with regards to our fantasies about robots, we might, for example, look at the promise (both realistic and unrealistic) some hold for robotics, or how transhumanists' enthusiasm for technology might be based on such positive projections and idealisations.
}

thought of as a way of managing anxiety. It is through such projections that we come to know and understand the world, through reality testing and emotional engagement. Into an unknown, uncertain space, we fantasise all sorts of things in order to defend ourselves against the greater fear of uncertainty and emptiness, or against the 'unthought knowns'-those things that we know, unconsciously, but that we cannot or wish not to face consciously (cf. Bollas 1987).

These processes have a vital role to play in all learning and experience, including normal, healthy development, and both normal and 'pathological' forms are evident in everyday life. The most obvious examples of such projections are instances of scapegoating, as commonly seen with racism (and here we see another all-too-familiar component of nationalism): It is not we who are violent, it is them. They hate us and are out to get us. As with the scapegoat, there is a belief that the container of the bad parts of the self must be destroyed before it can return and destroy us. This is a root of paranoia. The belief that we are being persecuted is our own fantasy.

We see the same processes at work in the construction of our monsters throughout the ages, in the barbaric brutality of racial others, in sexualised vampires and in consumerist zombies. The monster becomes a container for our own barbaric, imperialist practices, our own repressed sexuality, our own mindless pursuit of a promised ideal. And now we see the same processes in popular representations of robots. The Terminator, for example, or Star Trek's Borg are, among other things, projections of our own, very human, violent fantasies placed into an other, an other which then becomes a relentless, supremely destructive persecuting object. We fail to see that fear and anxiety and violence as our own, and imagine instead that it originates from the robot itself. But this evil robot is nothing more than our own violence, anxiety, hatred and fear imagined to exist in a mechanical cage; they become these bad versions of ourselves.

In Do Androids Dream of Electric Sheep?, the main character, Rick Deckard, provides us with a terrific example of how such projections operate. He is a bounty hunter, the epitome of the loner, who kills first and asks questions later, but Deckard nevertheless believes that it is the humanoid robot-the 'andy'-that is 'a solitary predator'. The narrator tells us, 'Rick liked to think of them that way; it made his job palatable' (Dick 1968).

Projections provide a defence against unwanted parts of the self. And though they are an integral part of normal development, a number of problems can arise from excessive or uncontrolled projections.

- When we project excessively, it leaves us empty, or feeling dead inside. This deadness we see reflected in 
our monsters, the robots and zombies that are so popular in contemporary fiction-monsters that are, quite literally, dead or soulless.

- Excessive splitting and projections can leave one feeling fragmented, in pieces. This is something we see in the dismemberment so commonly seen in representations of robots (and zombies), where broken-off pieces literally take on a life of their own.

- Projections can also be 'misplaced', that is, projected into an unsuitable container. Such a contained is incapable of returning or processing projections in a useful or appropriate way, which can lead to feelings of isolation or increasing the feelings of anxiety and persecution.

- Excessive projections can lead to feelings of depersonalisation, feelings of not being real. Psychoanalysts often describe such depersonalisation as being akin to feeling like an automaton, an empty object in a world empty of affect of feeling.

To summarise all of the above, our imagined monster robots are projections of our own anxieties and fears about ourselves and our cultural practices. Robots are containers for our projections, so our fear of robots is, at least in part, also a fear of our own rationalist selves.

\section{The robot as a projection of the rational human monster}

Frankenstein and his descendants-Mr. Hyde, zombies and all the robots we have come to fear, HAL 9000, the Terminator, the Borg, killer andys, etc. ${ }^{10}$-are created by our rationality, our industry and our science, and so these monsters reflect all of the fears that we associate with these other inventions: the inflexible logic of reason, the ruthless efficiency of industry, the emotional detachment of science. These monsters are not guided by hatred or vengeance or a fanatic devotion to irrational mythology, as with spectres or savage brutes or religious extremists. These soulless robotic monsters are made all the more potent and frightening by the fact that they are guided by a single principle: their violence and destruction is completely and utterly based in a calculated, indisputable logic, a resolute dedication to their technological, rational, scientific programming.

Robot monsters can therefore be seen as the living embodiment of those projected bad parts of our self, those negative parts of ourselves that we split off and lodge in an

\footnotetext{
${ }^{10}$ Though Robbie in Forbidden Planet (1956) is not a monster, we also see in Dr. Morbius such a Frankenstein figure, as he has unleashed a monster and claims to have been 'careful and, hopefully, dispassionate'.
}

external other. They are us, or, at least, those parts of ourselves that we come to fear when we look at our technological creations-rational, efficient, cold, mechanical, soulless and, ultimately, destructive.

It has often been pointed out that if a superior artificial intelligence was to create robot soldiers to wipe out the human race, then gun-wielding bipedal monsters would just about be the least efficient way of going about it (e.g. Armstrong 2014). And yet our fantasies persist in presenting us with humanoid-robot monsters. There is a simple logic for these robots' appearance, however: they are us. They look like us because that is what we see when we look into the mirror: an empty, violent, rational, mechanical shell. There is something about these robots, however-that otherwise resemble us to a large and completely unnecessary extent - that is missing, or that has been lost, that makes them less than human, and this reflects our own fears that we ourselves are becoming something less than human, and that we are destroying some essential part of our humanity in the process of becoming governed by rational programming.

Such a casting of robots as missing something essentially human has been evident for a long time, since the inception of stories about robots. With the very invention of the term robot, in Capek's play RUR, Rossum's Universal Robots (1920), there is this idea of the robot as a human lacking a particular human element, and this carries on in many of the stories told since. And this is true even those for whom robots are not 'evil': in the Alien series, Star Trek, Asimov's own writings, Forbidden Planet, etc., robots, both good and bad, are portrayed as devoid of emotion, lacking empathy or feeling, and governed only by reason and a predictable, programmable intellect.

Historical context is again particularly enlightening. Capek's play was staged in this period of increasing anxiety as to what was happening to us as a species, as a culture, in a period (i.e. the very late nineteenth, early twentieth century) and place (i.e. Western Europe) where there is much interest elsewhere in dissociative disorders (e.g. Freud), mechanisation (e.g. Frederick Winslow Taylor, F. T. Marinetti) and alienation (e.g. Marx et al.). Čapek's play reflects these concerns regarding dehumanisation in the light of mass industrialisation, the increasing mechanisation of killing seen during The Great War and a loss of certain pastoral conceptions of human experience in an increasingly urbanised world of technological innovations. And today, we can still see those very same anxieties that were first evident in Capek's robots: the same fear of the militarisation, as expressed in the headlines that greet each new, genuinely positive advance in robotics or prosthetics with dire warnings about the coming of terminators or Cybermen; and the dehumanisation of human relationships and the loss of jobs to mechanical systems, as 
expressed in the intense speculation, in both the popular press and from more reputable sources, suggesting that robots are about to steal all of our jobs (cf. Frey and Osborne 2013; House of Lords Digital Skills Committee 2015).

But what makes robots particularly terrifying monsters-and especially suitable vehicles for our anxieties about ourselves-is that while they become containers for our fears about our rationality, the monster robots are not only incessantly, unceasingly rational; they are also containers for all of those other darker, non-rational impulses that have haunted human (un)consciousness for so many millennia. Robots are all the more terrifying because they represent both the horrors of reason-the inflexible doctrine of rationality, the precision and productivity of technology, the dispassionate methodology of science-and our animalistic impulses: the irrational violence, the impulsive desires for domination and control. And because these are really our fears about ourselves, these robots really are inescapable: we just pretend that it's not $u s$, it's them.

To regard robots in this way is not symptomatic of technophobia; to understand fictional robots in this way is not anti-science, or anti-industry. And this is not an argument to eschew technological progress, such as that made by Alquist, the Tolstoyan hero of $R U R$, or to suggest that we forgo reason and put an end to the remarkable process that is being made with living machines and pause to embrace our 'inner fairy', merely to preserve some outmoded notion of 'humanity'. Our conceptions of ourselves are all constructed notions, and these arguments are not meant to endorse some Romantic idea of 'human nature' or some kind of naïve genuine self to which we must ultimately be true. It is important that we remember what Asimov says regarding humanity's seemingly endless struggle with these anxieties: 'Faust must indeed face Mephistopheles, but Faust does not have to be defeated!' (Asimov 1947).

Anxieties do not have to be based on sound, sober judgement to have real consequences; in fact, it rarely works out that way. Often, the more outrageously fantastical the anxiety, the more it takes hold of us and takes control of us. However, anxieties are very rarely useless, and almost always tell us something very interesting and profound about our relationship with ourselves and with our world, or at least with how we view our relationship with ourselves and the world. In analysing these representations of monstrous robots, we can therefore gain great insight into the fears-genuine or naïve-that the public harbours towards new advancements in technology, insights that can inform those working with and designing living machines as to how their inventions might be received. But we also learn something about anxieties that people have regarding their own conception of self, and how that is changing in an increasingly scientific, rational, technological world.

We need to learn to be more ambivalent about robots and our relationships with them, to regard both positive and negative in an informed and balanced way. There is some reason for optimism, in that popular representations of robots seem to be increasingly positive, or at least ambivalent. Yes, the robots are still more often than not The Baddies, but they are also increasingly, if not The Goodies, at least offering certain solutions to the problems of human existence, including our anxieties of rationalist, mechanical dehumanisation. Daniel H. Wilson's recent novels Robopocalypse (2011) and Amped (2012) are two examples, Pacific Rim (del Toro 2013) is another, and even if we look at The Terminator films, by the second film, Arnie is already a Good Guy helping John Connor (a trend that becomes more prevalent in the subsequent instalments in the franchise); so evidently there is some hope.

Acknowledgments The author wishes to thank the feedback on some of these ideas from the Living Machines Conference in London, August 2013, particularly Dr. Joanna Bryson. Thanks are also due to ongoing discussions with Prof. Tony Prescott, Dr. Stuart Wilson, Prof. Adam Piette, Dr. Fabienne Collignon, and others at the Department of Psychology and School of English, University of Sheffield, Martyn Gray, and feedback from AI and Society reviewers.

Open Access This article is distributed under the terms of the Creative Commons Attribution 4.0 International License (http:// creativecommons.org/licenses/by/4.0/), which permits unrestricted use, distribution, and reproduction in any medium, provided you give appropriate credit to the original author(s) and the source, provide a link to the Creative Commons license, and indicate if changes were made.

\section{References}

Anzieu D (1984) The group and the unconscious. Routledge, London Armstrong S (2014) Smarter than us: the rise of machine intelligence. Machine Intelligence Research Institute, Berkeley

Asimov I (1947) Little lost robot. In: Robot dreams, 1986. Accessed as Kindle edition, 2013

Bion WR (1962) Learning from experience. Pitman, London

Bollas C (1987) The Shadow of the object. Free Associations, London

Čapek K (1920) R.U.R. (Rossum's Universal Robots) (trans: Novack C). Penguin, London (2004)

del Toro G (2013) Pacific rim. Warner Bros, Burbank

Dick PK (1968) Do androids dream of electric sheep? Kindle edition (2013)

Frey CB, Osborne MA (2013) The future of employment: how susceptible are jobs to computerisation? http://www.oxfordmartin. ox.ac.uk/downloads/academic/The_Future_of_Employment.pdf

Gill Karamjit S (2013) Faust, Freud, machine: encounters and performance. AI Soc 28:253-255

Green A (1993) The dead mother. Psyche 47(3):205-240 
House of Lords, Digital Skills Committee (2015) Make or break: the UK's digital future. http://www.publications.parliament.uk/pa/ ld201415/ldselect/lddigital/111/111.pdf

Klein M (1946) Notes on some schizoid mechanisms. Envy and Gratitude (1988). Virago, London, pp 1-24

Schuler D (2013) Doctor Faustus in the twenty-first century: a meditation on knowledge, power and civic intelligence. AI Soc 28:257-266
Scott R (1982) Blade runner. Warner Bros, Burbank

Shelley M (1818) Frankenstein; or, the modern Prometheus. Penguin, London

Wilson DH (2011) Robopocalypse. Simon and Schuster, London

Wilson DH (2012) Amped. Simon and Schuster, London

Young RM (1994) Mental space. Free Associations, London 